\title{
NUMERICAL SIMULATION ON LAMINAR FREE-CONVECTION FLOW AND HEAT TRANSFER OVER AN ISOTHERMAL VERTICAL
}

\author{
PLATE
}

\author{
Asish Mitra ${ }^{1}$ \\ ${ }^{1}$ Associate Prof. \& HOD-BSH Dept, College of Engineering \& Management, Kolaghat. East Midnapur, West Bengal. \\ India
}

\begin{abstract}
In the present numerical study, laminar free-convection flow and heat transfer over an isothermal vertical plate is presented. By means of similarity transformation, the original nonlinear coupled partial differential equations of flow are transformed to a pair of simultaneous nonlinear ordinary differential equations. Then, they are reduced to first order system. Finally, NewtonRaphson method and adaptive Runge-Kutta method are used for their integration. The computer codes are developed for this numerical analysis in Matlab environment. Velocity and temperature profiles for various Prandtl number are illustrated graphically. Flow and heat transfer parameters are derived as functions of Prandtl number alone. The results of the present simulation are then compared with experimental data published in literature and find a good agreement.
\end{abstract}

Keywords: Free Convection, Heat Transfer, Matlab, Numerical Simulation, Vertical Plate.

\section{List of Symbols}

F function defined in eq (6)

g gravitational acceleration, $9.81 \mathrm{~m} / \mathrm{s}^{2}$

$\mathrm{G}$ function defined in eq (9)

$\mathrm{Gr}_{\mathrm{x}}$ Grashof number based on $\mathrm{x}$, dimensionless

$\mathrm{h}$ heat transfer coefficient, $\mathrm{W} / \mathrm{m}^{2} . \mathrm{K}$

$\mathrm{k}$ thermal conductivity, $\mathrm{W} / \mathrm{m} . \mathrm{K}$

$\mathrm{Nu}$ Nusselt number, dimensionless

Pr Prandtl number, dimensionless

$\mathrm{T}$ temperature, $\mathrm{K}$

$\mathrm{T}_{\mathrm{s}}$ surface temperature, $\mathrm{K}$

$T_{\infty}$ free streams temperature, $\mathrm{K}$

$\mathrm{u}$ velocity component in $\mathrm{x}, \mathrm{m} / \mathrm{s}$

$\mathrm{v}$ velocity component in $\mathrm{y}, \mathrm{m} / \mathrm{s}$

$\mathrm{x}$ coordinate from the leading edge, $\mathrm{m}$

$\mathrm{y}$ coordinate normal to plate, $\mathrm{m}$

$\mathrm{U}$ dimensionless velocity component in $\mathrm{x}$

$\mathrm{V}$ dimensionless velocity component in $\mathrm{y}$

$\mathrm{z}_{1}, \mathrm{z}_{2}, \mathrm{z}_{3}, \mathrm{z}_{4}, \mathrm{z}_{5}$ variables, eq (13)

\section{Greek Symbols}

$\beta$ coefficient of thermal expansion, 1/K

$\alpha$ thermal diffusivity, $\mathrm{m}^{2} / \mathrm{s}$

$\mu \quad$ dynamic viscosity, N.s $/ \mathrm{m}^{2}$

$v$ kinematic viscosity, $\mathrm{m}^{2} / \mathrm{s}$

$\eta$ similarity variables, eq (5)

$\tau$ shear stress, $\mathrm{N} / \mathrm{m}^{2}$

$\psi$ stream function, $\mathrm{m}^{2} / \mathrm{s}$

\section{INTRODUCTION}

The free convection problem on a vertical plate has been studied in various ways: Pohlhausen [1], Schmidt and Beckmann [2], Ostrach [3], LeFevre [4], Finston [5], Finston [5], Sparrow and Gregg [6], Foote [7], Kuiken [8], Kao [9], and Elbashbeshy [10], The problem is also discussed in several text books [11-15].

In the present numerical investigation, a simple accurate numerical simulation of laminar free-convection flow and heat transfer over an isothermal vertical plate is developed.

The paper is organized as follows: Mathematical model of the problem, its solution procedure, development of code in Matlab, interpretation of the results, comparison with experimental data.

\section{MATHEMATICAL MODEL}

We consider a vertical hot flat plate immersed in a quiescent fluid body. We assume the natural convection flow to be steady, laminar, two-dimensional, no dissipation, and the fluid to be Newtonian with constant properties, including density, with one exception: the density difference $\rho-\rho_{\infty}$ is to be considered since it is this density difference between the inside and the outside of the boundary layer that gives rise to buoyancy force and sustains flow. (This is known as the Boussinesq approximation.) We take the upward direction along the plate to be $x$, and the direction normal to surface to be $y$, as shown in Figure 1 .

\section{Subscript \\ s plate surface \\ $\infty$ free stream}




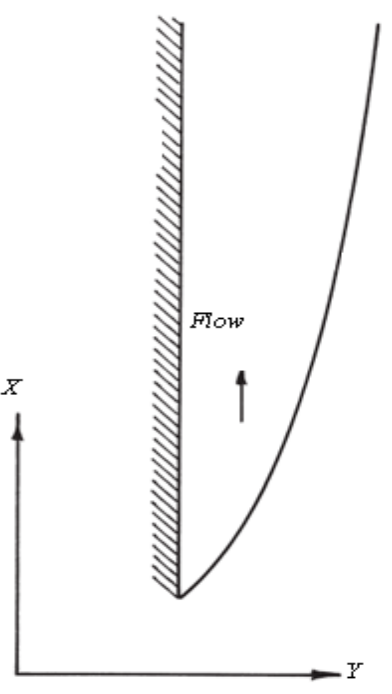

Fig 1. Physical Model and its coordinate system

The equations governing the flow are

$$
\begin{aligned}
& \frac{\partial u}{\partial x}+\frac{\partial v}{\partial y}=0 \\
& u \frac{\partial u}{\partial x}+v \frac{\partial u}{\partial y}=v \frac{\partial^{2} u}{\partial y^{2}}+\beta g\left(T-T_{\infty}\right) \\
& u \frac{\partial T}{\partial x}+v \frac{\partial T}{\partial y}=\alpha \frac{\partial^{2} T}{\partial y^{2}}
\end{aligned}
$$

The boundary conditions on the solution are:

At $\mathrm{y}=0: \mathrm{u}=\mathrm{v}=0, \mathrm{~T}=\mathrm{T}_{\mathrm{s}}$

$$
\text { For large } \mathrm{y}: \mathrm{u} \rightarrow 0, \mathrm{~T} \rightarrow \mathrm{T}_{\infty}
$$

A similarity solution to this problem has been obtained by Ostrach [2]. The solution involves transforming variables by introducing a similarity parameter of the form

$$
\eta=\frac{y}{x}\left[\frac{G r_{x}}{4}\right]^{1 / 4}
$$

and representing the velocity components in terms of a stream function defined as

$$
\psi(x, y)=F(\eta)\left[4 v\left(\frac{G r_{x}}{4}\right)^{1 / 4}\right]
$$

where $\mathrm{Gr}_{\mathrm{x}}$ is the Grashof number based on $\mathrm{x}$, i.e.,

$$
G r_{x}=\frac{g \beta\left(T_{s}-T_{\infty}\right) x^{3}}{v^{2}}
$$

With the foregoing definition of the stream function, the velocity components may be expressed as

$$
\begin{gathered}
u=\frac{\partial \psi}{\partial y}=\frac{\partial \psi}{\partial \eta} \frac{\partial \eta}{\partial y}=4 v\left(\frac{G r_{x}}{4}\right)^{1 / 4} F^{\prime}(\eta) \frac{1}{x}\left(\frac{G r_{x}}{4}\right)^{1 / 4} \\
=\frac{2 v}{x} G r_{x}^{1 / 2} F^{\prime}(\eta) \\
v=-\frac{\partial \psi}{\partial x}=-\frac{\partial \psi}{\partial \eta} \frac{\partial \eta}{\partial x} \\
=\frac{v}{x}\left(\frac{G r_{x}}{4}\right)^{1 / 4}\left[\eta F^{\prime}(\eta)-3 F(\eta) x^{1 / 4}\right]
\end{gathered}
$$

The prime, of course, denotes differentiation with respect to $\eta$.

Now, introducing the dimensionless temperature

$$
\frac{T-T_{\infty}}{T_{s}-T_{\infty}}=G(\eta)
$$

the three original partial differential equations (1) to (3) may then be reduced to two ordinary differential equations of the form

$$
F^{\prime \prime \prime}+3 F F^{\prime \prime}-2\left(F^{\prime}\right)^{2}+G=0
$$

$$
G^{\prime \prime}+3 \operatorname{Pr} F G^{\prime}=0
$$

where $\operatorname{Pr}=\frac{c_{p} \mu}{k}$, Prandtl number of the fluid.

The continuity equation (1) is automatically satisfied through introduction of the stream function. Eqs (10) and (11) constitute a pair of simultaneous nonlinear ordinary differential equations for the velocity and temperature functions, F' and G. They must be solved subject to the following boundary conditions:

At $y=0: u=0$ i.e., at $\eta=0: F^{\prime}=0$

At $y=0: v=0$ i.e., at $\eta=0: F=0$

At $y=0: T=T_{s}$ i.e., at $\eta=0: G=1$

For large $y: u \rightarrow 0$ i.e., for large $\eta: F^{\prime}=0$

For large $y: T \rightarrow T_{\infty}$ i.e., for large $\eta: G=0$

The fact that the original partial differentials have been reduced to a pair ordinary differential equations confirms the assumptions that similarity solutions do in fact exist. 


\section{SOLUTION PROCEDURE}

Eqs (10) and (11) are coupled and must be solved simultaneously, which is always the case in free-convection problems. No analytic solution is known, so numerical integration is necessary. There are two unknown initial values at the wall. One must find the proper values of F' $(0)$ and $G^{\prime}(0)$ which cause the velocity and temperature to vanish for large $\eta$. The Prandtl number is a parameter.

The original approximate solutions given Pohlhausen [1] in 1930 were improved with digital-computer solutions provided by Ostrach [ 3] and others in 1953.

\subsection{Reduction of Equations to First-Order System}

This is done easily by defining new variables:

$z_{1}=F$

$z_{2}=\dot{z}_{1}=\dot{F}$

$z_{3}=\dot{z}_{2}=\ddot{z}_{1}=\ddot{F}$

$\dot{z}_{3}=\ddot{z}_{2}=\dddot{z}_{1}=\dddot{F}=-3 z_{1} z_{3}+2 z_{2}^{2}-z_{4}$

$z_{4}=G$

$z_{5}=\dot{z}_{4}=\dot{G}$

$\dot{z}_{5}=\ddot{z}_{4}=\ddot{G}=-3 \operatorname{Pr} z_{1} z_{5}$

with the following boundary conditions:

$$
\begin{aligned}
& z_{1}(0)=F(0)=0 \\
& z_{2}(0)=z_{1}(0)=\dot{F}(0)=0 \\
& z_{2}(\infty)=z_{1}(\infty)=\dot{F}(\infty)=0 \\
& z_{4}(0)=G(0)=1 \\
& z_{4}(\infty)=G(\infty)=0
\end{aligned}
$$

$\mathrm{Eq}(10)$ is third-order and is replaced by three first-order equations, whereas eq(11) is second-order and is replaced with two first-order equations.

Three of the boundary conditions are specified at $\eta=0$, while the remaining two at $\eta=\infty$. One way to overcome the lack of starting conditions is to guess the missing boundary values. Since F' and G' are proportional to the velocity gradient and temperature gradient, F', should be positive and $\mathrm{G}^{\prime}$ negative at $\eta=0$. The initial guessed values are altered to obtained to obtained solutions at higher values of Prandtl number.

\subsection{Solution to Initial Value Problems}

To solve Eq(13), we denote the two unknown initial values by $\mathrm{u} 1$ and $\mathrm{u} 2$, the set of initial conditions is then:
$z_{1}(0)=F(0)=0$

$z_{2}(0)=z_{1}(0)=F(0)=0$

$z_{3}(0)=z_{2}(0)=z_{1}(0)=\ddot{F}(0)=u_{1}$

$z_{4}(0)=G(0)=1$

$z_{5}(0)=z_{4}(0)=G(0)=u_{2}$

If Eqs (10) and (11) are solved with adaptive Runge-Kutta method using the initial conditions in $\mathrm{Eq}(15)$, the computed boundary values at $\eta=\infty$ depend on the choice of $\mathrm{u}_{1}$ and $\mathrm{u}_{2}$. We express this dependence as

$$
\begin{aligned}
& z_{2}(\infty)=z_{1}(\infty)=F(\infty)=f_{1}\left(u_{1}, u_{2}\right) \\
& z_{4}(\infty)=G(\infty)=f_{2}\left(u_{1}, u_{2}\right)
\end{aligned}
$$

The correct choice of $\mathrm{u}_{1}$ and $\mathrm{u}_{2}$ yields the given boundary conditions at $\eta=\infty$; that is, it satisfies the equations

$$
\begin{aligned}
& f_{1}\left(u_{1}, u_{2}\right)=0 \\
& f_{2}\left(u_{1}, u_{2}\right)=0
\end{aligned}
$$

These are simultaneous nonlinear equations that can be solved by the Newton-Raphson method. A value of 10 is fine for infinity, even if we integrate further nothing will change.

\subsection{Program Details}

This section describes a set of Matlab routines for the solution of eqns (10) and (11) along with the boundary conditions (12). They are listed in Table 1.

Table 1: A set of Matlab routines used sequentially to solve Equations (10) \& (11).

\begin{tabular}{|l|l|}
\hline Matlab code & Brief Description \\
\hline deqs.m & $\begin{array}{l}\text { Defines the differential equations } \\
(10) \text { and }(11) .\end{array}$ \\
\hline incond.m & $\begin{array}{l}\text { Describes initial values for } \\
\text { integration, } \mathrm{u}_{1} \text { and } \mathrm{u}_{2} \text { are guessed } \\
\text { values, eq }(15)\end{array}$ \\
\hline runKut5.m & $\begin{array}{l}\text { Integrates the initial value problem } \\
(13) \text { using adaptive Runge-Kutta } \\
\text { method. }\end{array}$ \\
\hline residual.m & $\begin{array}{l}\text { Provides boundary residuals and } \\
\text { approximate solutions. }\end{array}$ \\
\hline newtonraphson. & $\begin{array}{l}\text { Provides correct values } \mathrm{u}_{1} \text { and } \mathrm{u}_{2} \\
\text { using approximate solutions from } \\
\text { residual.m }\end{array}$ \\
\hline runKut5.m & $\begin{array}{l}\text { Again integrates the initial value } \\
\text { problem }(13) \text { using correct values } \\
\text { of } \mathrm{u}_{1} \text { and } \mathrm{u}_{2} .\end{array}$ \\
\hline
\end{tabular}


The output of the code runKut5.m gives the tabulated values of $F, F$ ', F', G, G' as function of $\eta$ for various values of Prandtl number.

\section{INTERPRETATION OF THE RESULTS}

\subsection{Dimensionless Velocity and Temperature Profiles}

Physical quantities are related to the dimensionless functions F and G through Eqs (5), (8) and (9). F and G are now known. Some typical velocity and temperature profiles obtained using this procedure are shown in Figs (2) and (3). Some accurate initial values from this computation are listed in Table 2. These theoretical profiles are in good agreement with experimental laminar free-convection data on isothermal vertical plates.

Table 2. Computed parameters from Eqs (10) \& (11)

\begin{tabular}{|l|l|l|}
\hline $\operatorname{Pr}$ & $F^{\prime \prime}(0)$ & $-G(0)$ \\
\hline 0.01 & 0.947 & 0.118 \\
\hline 0.05 & 0.899 & 0.179 \\
\hline 0.10 & 0.856 & 0.234 \\
\hline 0.50 & 0.713 & 0.442 \\
\hline 0.72 & 0.676 & 0.505 \\
\hline 1.0 & 0.642 & 0.567 \\
\hline 2.0 & 0.571 & 0.717 \\
\hline 3.0 & 0.531 & 0.816 \\
\hline 6.0 & 0.465 & 1.008 \\
\hline 10.0 & 0.420 & 1.170 \\
\hline 20.0 & 0.362 & 1.423 \\
\hline 30.0 & 0.332 & 1.591 \\
\hline 50.0 & 0.296 & 1.826 \\
\hline 100.0 & 0.252 & 2.194 \\
\hline 1000.0 & 0.145 & 3.970 \\
\hline
\end{tabular}

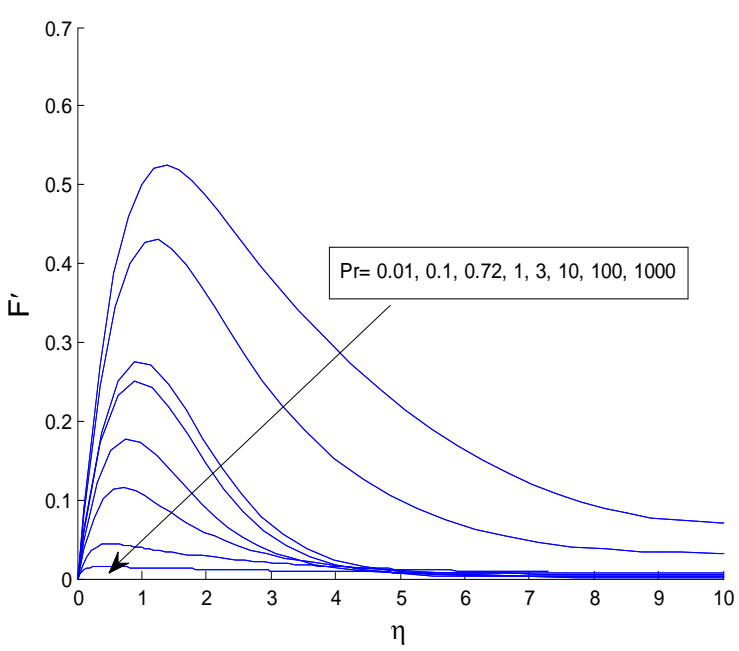

Fig 2. Dimensionless velocity distributions for various Prandtl numbers

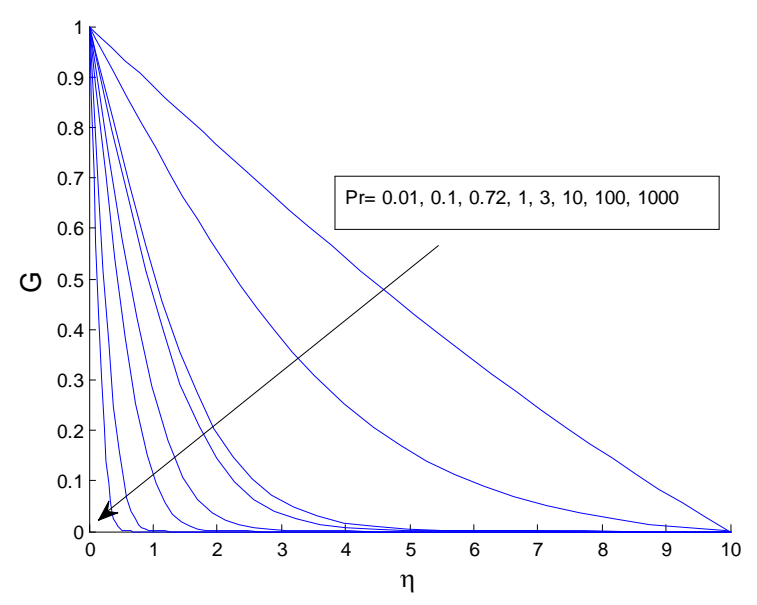

Fig 3. Dimensionless temperature distributions for various Prandtl numbers

\subsection{Flow and Heat Transfer Parameters}

Besides the velocity and temperature distributions, it is often desirable to compute other physically important quantities (for example, shear stress, drag, heat-transfer-rate) associated with the free-convection flow.

Shear stress is defines as:

$$
\tau=\mu\left(\frac{\partial u}{\partial y}\right)_{y=0}
$$

From Eqs (5) and (8), we can write

$$
\frac{\partial u}{\partial y}=\frac{2 v}{x^{2}}\left(\frac{G r_{x}}{4}\right)^{1 / 4} F^{\prime \prime}(\eta)
$$

Substituting this expression into (17), we get the flow parameter

$$
\frac{\tau}{\frac{2 v}{x^{2}}\left(\frac{G r_{x}}{4}\right)^{1 / 4}}=F^{\prime \prime}(0)
$$

The flow parameter is presented in Fig (4). From this figure, various flow quantities for a given set of conditions can be computed. 


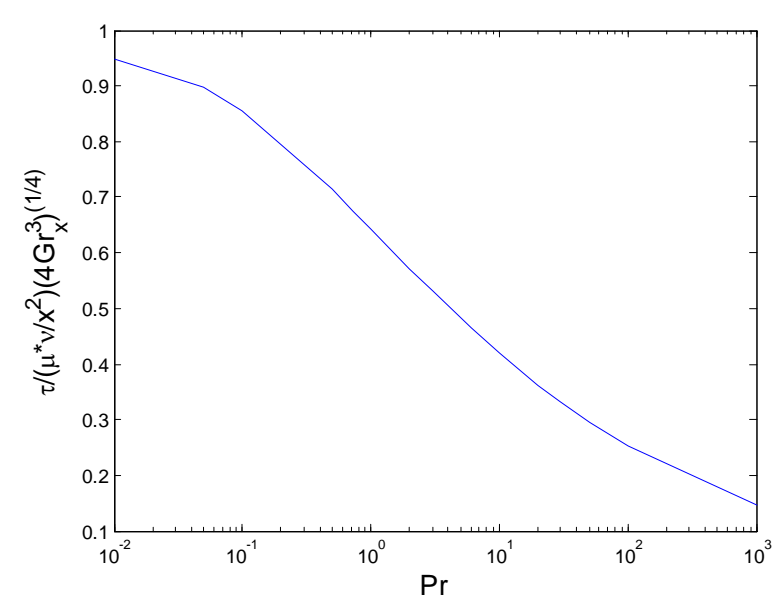

Fig 4. Dimensionless flow parameter as function of Prandtl number

Heat flux at the plate surface is:

$$
-k\left(\frac{\partial T}{\partial y}\right)_{y=0}=h\left(T_{s}-T_{\infty}\right)
$$

Accordingly, local Nusselt number can be written as

$$
N u_{x}=\frac{h x}{k}=-\frac{x}{\left(T_{s}-T_{\infty}\right)}\left(\frac{\partial T}{\partial y}\right)_{y=0}
$$

From eqs (5) and (9), we can write

$\frac{\partial T}{\partial y}=\frac{\partial T}{\partial \eta} \frac{\partial \eta}{\partial y}$

$=\frac{\partial}{\partial \eta}\left[T_{\infty}+G(\eta)\left(T_{s}-T_{\infty}\right)\right] \frac{\partial}{\partial y}\left[\frac{y}{x}\left(\frac{G r_{x}}{4}\right)^{1 / 4}\right]$

$=\left(T_{s}-T_{\infty}\right) G^{\prime}(\eta) \frac{1}{x}\left(\frac{G r_{x}}{4}\right)^{1 / 4}$

$=\frac{\left(T_{s}-T_{\infty}\right)}{x}\left(\frac{G r_{x}}{4}\right)^{1 / 4} G^{\prime}(\eta)$

Substitution of this expression into eq (20) yields the heattransfer parameter

$$
\frac{N u_{x}}{\left(G r_{x} / 4\right)^{1 / 4}}=-G^{\prime}(0)
$$

It is a function of only Prandtl number, shown in Fig.5. Le Fevre [4] developed the semi-empirical formula (22) from numerical solutions to Pohlhausen's approximation [1] as:

$$
N u_{x}=\left(\frac{G r_{x}}{4}\right)^{1 / 4} \frac{0.75 \operatorname{Pr}^{1 / 2}}{\left(0.609+1.221 \operatorname{Pr}^{1 / 2}+1.238 \operatorname{Pr}\right)^{1 / 4}}
$$

Figure 5 illustrates the comparison of the present computation (21) with the semi-empirical formula (22).

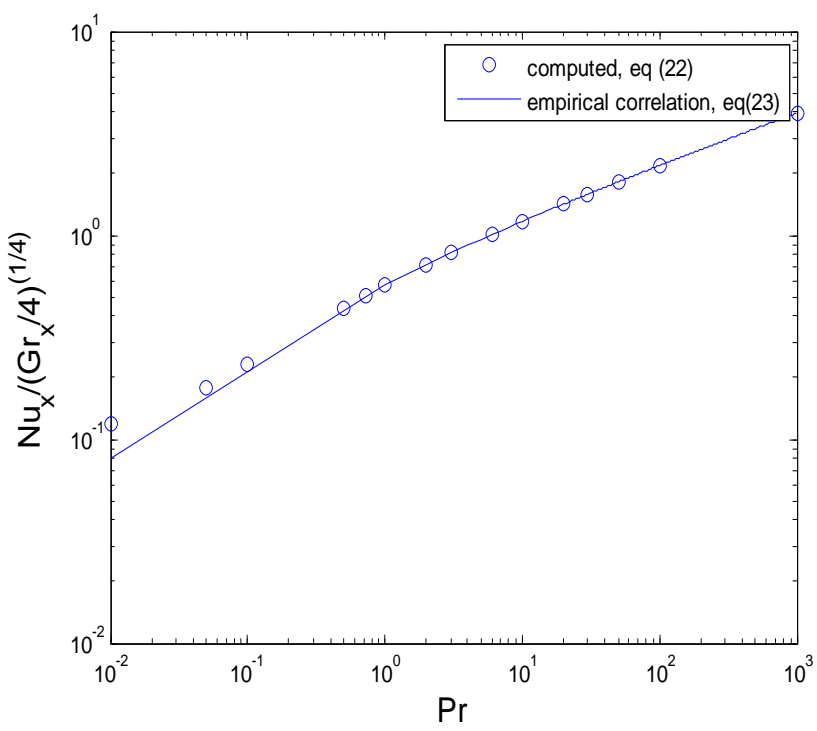

Fig 5. Comparison of the present computation with semiempirical formula.

Local Nusselt number can be calculated from this equation, for example

For $\operatorname{Pr}=0.72$ and $\mathrm{Gr}_{\mathrm{x}}=10^{9}$

$$
N u_{x}=\left(G r_{x} / 4\right)^{1 / 4} \times-G^{\prime}(0)=\left(\frac{10^{9}}{4}\right)^{1 / 4} \times 0.5046=63.45
$$

This indicates that large heat transfer coefficients can be obtained with free convection flows.

\section{COMPARISON OF RESULTS WITH PREVIOUS WORK}

Laminar free-convection flows of air as generated by gravitational forces about isothermal vertical flat plates were made by Schmidt and Beckmann [2] in which velocity measurements at various points along the plate were made by means of a quartz-filament anemometer and the temperature measurements were obtained by means of manganeseconstantan thermocouples. In particular, they measured velocity and temperature for a $12.5-\mathrm{cm}$-high vertical plate for the conditions $\mathrm{T}_{\mathrm{s}}=65^{\circ} \mathrm{C}$ and $\mathrm{T}_{\infty}=15^{\circ} \mathrm{C}$. By dimensionalizing the solution (Figs. $2 \& 3$ ), i.e., eqs (5), (8) and (9), we can compute the dimensional velocity and temperature as a function of $y$ at a particular value of $x$ :

$$
y=\eta x\left(\frac{4}{G r_{x}}\right)^{1 / 4}
$$




$$
\begin{array}{r}
u=\frac{2 v}{x} F^{\prime}(\eta) G r_{x}^{1 / 4} \\
T=T_{\infty}+G\left(T_{s}-T_{\infty}\right)
\end{array}
$$

The velocity and temperature profiles of air for the above mentioned experimental conditions $\left(\mathrm{T}_{\mathrm{s}}=65^{\circ} \mathrm{C}, \quad \mathrm{T}_{\infty}=15^{\circ} \mathrm{C}\right)$ obtained from these computations are then compared with the experimental data of Schmidt and Beckmann. Figures 6 and 7 illustrate the comparison of the present numerical work with experimental data.

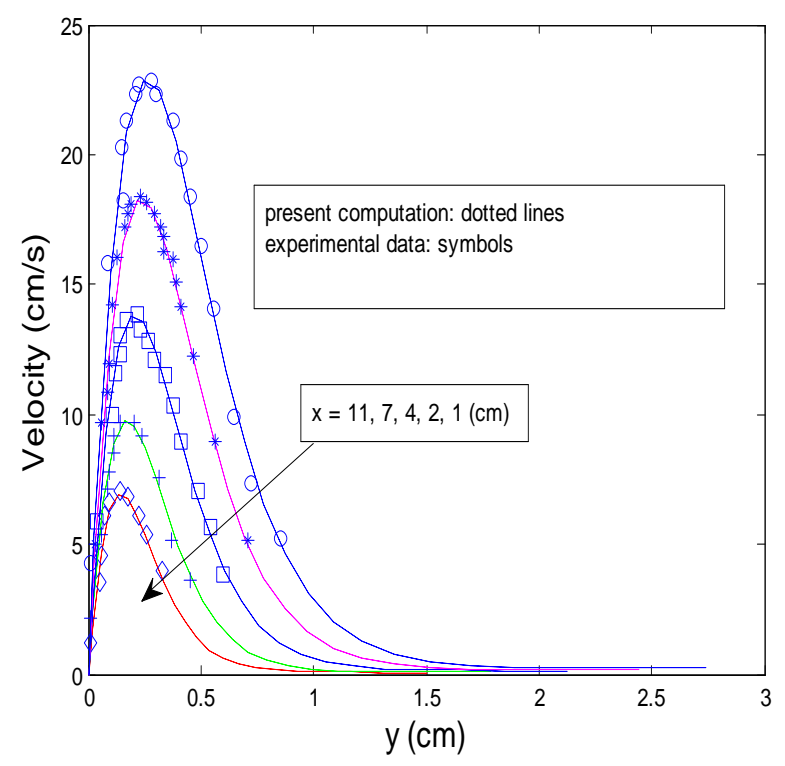

Fig 6. Comparison of the computed velocity profiles with experimental data.

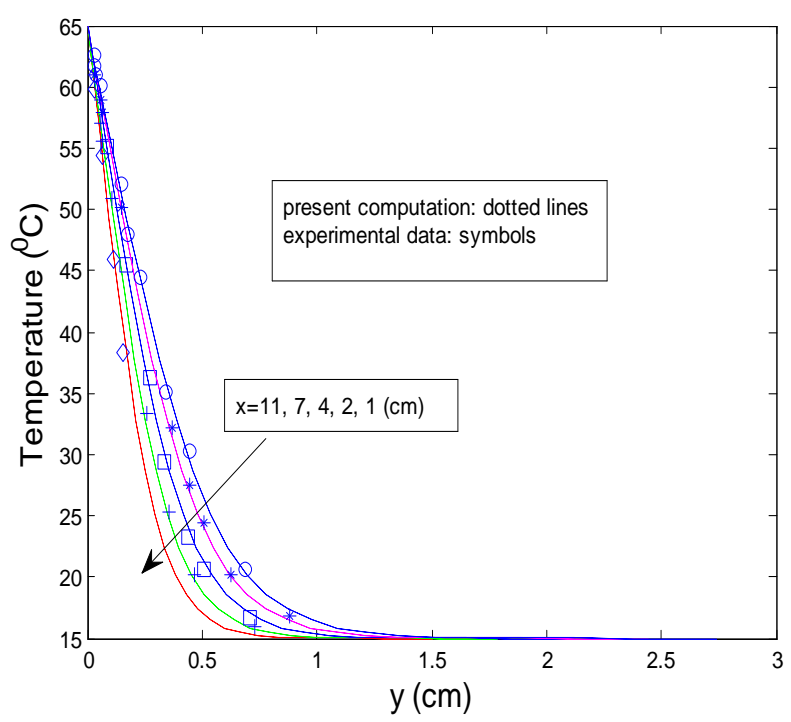

Fig 7. Comparison of the computed temperature profiles with experimental data.

\section{CONCLUSION}

In the present numerical simulation, laminar free-convection flow and heat transfer over an isothermal vertical plate is presented. Details of the solution procedure of the nonlinear coupled partial differential equations of flow are discussed. The computer codes are developed for this numerical analysis in Matlab environment. Velocity and temperature profiles for Prandtl numbers of 0.01, 0.05, 0.1, 0.5, 0.72, 1, 2, $3,6,10,20,30,50,100$ and 1000 are computed using these codes. The computed and experimental velocity and temperature distributions are in good agreement. Flow and heat transfer parameters (giving physically important quantities such as shear stress, drag, heat-transfer-rate) are derived as functions of Prandtl number alone. The computed results of the present simulation are compared with frequently used semi empirical heat transfer correlation and find a good agreement. A good agreement between the present results and the past indicates that the present numerical simulation may be an efficient and stable numerical scheme in natural convection.

\section{REFERENCES}

[1]. Pohlhausen, E.: Der Wurmeaustausch zwischen festen Krpern und Flüssigkeiten mit kleiner Reibung und kleiner Wurmeleitung. Z. Angew. Math. Mech. 1, 115-121 (1921).

[2]. E. Schmidt and W. Beckmann, Tech. Mech. U. Thermodynamik, 1, 341 and 391 (1930).

[3]. S. Ostrach, "An Analysis of Laminar Free-Convection Flow and Heat Transfer About a Flat Plate Parallel to the Direction of the Generating Body Force," National Advisory Committee for Aeronautics Technical Note, No. 2635, 1952.

[4]. E. J. Le Fevre, "Laminar Free Convection from a Vertical Plane Surface," Proc. 9th Int. Congress Applied Mechanics ,Brussels, Vol. 4, pp. 168-174 (1956).

[5]. Finston, M., "Free Convection past a Vertical Plate", Journal of Applied Mathematical Physics (ZAMP) 7, pp. 527 $-529,1956$.

[6]. Sparrow, E.M. and Gregg, J.L., "Similar Solutions for Laminar Free Convection from a Nonisothermal Vertical Plate", Trans. ASME, Journal of Heat Transfer 80, pp. 379387, 1958.

[7]. Foote, J.R., “An Asymtotic Method for Free Convection Past a Vertical Plate", Journal of Applied Mathematical Physics (ZAMP) 9, pp. $64-67,1958$.

[8]. Kuiken, H.K., "General Series Solution for Free Convection Past a Non-Isothermal Vertical Flat Plate", Applied Scientific Research 20, pp. 205 - 215, 1969

[9]. Kao, T.T., "Locally Nonsimilar Solution for Laminar Free Convection Adjacent to a Vertical Wall", Journal of Heat Transfer 98, pp. 321 - 322, 1976.

[10]. Elbashbeshy, E.M.A., "Free Convection Flow with Variable Viscosity and Thermal Diffusivity along a Vertical Plate in the Presence of the Magnetic Field", International Journalof Engineering Science 38, pp. 207 - 213, 2000.

[11]. Bejan, A., Heat Transfer, John Wiley, New York, 1993. [12]. Incropera, F.P. and DeWitt D.P., Introduction to Heat Transfer, Fourth edition, John Wiley, New York, 2002.

[13]. Çengel, Y.A., Heat Transfer, Second edition, McGrawHill, New York, 2003. 
[14]. Lienhard IV, J.H. and Lienhard V, J.H., A Heat Transfer Textbook, Phlogiston Press, Cambridge, MA, 2003.

[15]. Nellis, G. and Klein, S., Heat Transfer, Cambridge University Press, London, UK, 2008.

\section{BIOGRAPHY}

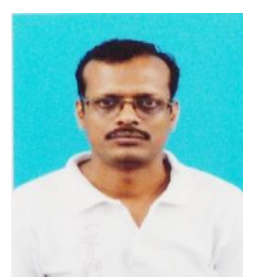

Dr. Asish Mitra did M.Sc. in Physics in Presidency College, and $\mathrm{PhD}$ and post $\mathrm{PhD}$ research work on Heat Transfer and $\mathrm{CFD}$ in Jadavpur University. $\mathrm{He}$ is presently Associate Professor \& HOD of the Department of Basic Science \& Humanities of College of Engineering \& Management, Kolaghat, East Midnapur, West Bengal. He is having more than 12 years post-PhD teaching experience in Physics at UG level. $\mathrm{He}$ is a regular reviewer of the International Journals "Heat and Mass Transfer" and "WSEAS" (World Scientific \& Engineering Academy \& Society). He is the author of 06 papers in International Journals, 14 papers in International Conferences and 06 papers in Seminars. He has completed a CSIR-sponsored project as Co-investigator and organized 04 National Workshops and 01 International Conference as convener. His field of research is Computational Heat Transfer and Fluid Flow. 